\title{
The construction and implementation of security intelligent lock model based on situation calculus*
}

\author{
Wei-Hong Wang, Da-Wei Zhang, Bao-Qin Zhao, \\ Su-Hua Han and Fu-Xiang Zhou \\ Institute of Information and technology Hebei University of \\ Economics and Business, \\ Shijiazhuang 050000, China \\ E-mail:Wangwhs@163.com
}

\begin{abstract}
Aiming at the problem that it lacks the effective logic verification model on the security and control mechanism of intelligent lock, this paper proposed a novel security intelligent lock model based on situation calculus, named SILM-SC. Firstly, based on the research and application about the security intelligence lock, and integrated the demands on security and mobility, the logic process of security intelligent lock is deeply discussed. Subsequently, SILM-SC is established according to the logic process, and it fully considers the practical needs of the users and draws on the logical thinking of the situation calculus to make up for the lack of logic verification of security intelligent lock. Finally, according to the model, the security intelligence lock is set up, and the security of the model is proved by scientific test.
\end{abstract}

Keywords: Security intelligence lock; Situation calculus; Mobile intelligence.

\section{Introduction}

Today, the development of computer software and hardware is in high speed parallel, The security and intelligence of security infrastructure has become a hot spot and focus, And the core of these facilities, in fact, is still a variety of locks. At present, the market can be broadly divided into two categories: mechanical lock and electronic lock[1].The principle of different locks is different and it has its own unique advantages, but there are some drawbacks, such as low security, inconvenience, easy damage and low accuracy[2-5].

Except for the above problems, there is no formal method to verify the security and tightness of locks at present. Aiming at these problems and taking into account the popularity of mobile intelligent devices at the same time, this article intends to use the mobile smart devices as a key and whole system

\footnotetext{
${ }^{*}$ This paper is supported by research projects C201400313,C2015003042.
} 
through the three handshake to ensure the safety of the lock. Before this, the whole process of unlocking is verified by using the scenario calculus.

\section{Related Work}

\subsection{Research and Application About the Security Lock}

Since ancient times, people's life has been accompanied by the lock. Mechanical lock[6] is composed of many physical components and used in the family. Electronic lock can be divided into three categories button type electronic lock, card type electronic lock and biometric electronic lock [2]. Most of them are used in high grade places such as libraries, research institutes, hotels, etc.

\subsection{Security and Mobility About the Security Intelligence Lock}

It can be known that most of the current existence of the lock has a variety of weakness, such as low security, not easy to carry, easy damage, high cost[2-5]. In our country everyone hold a mobile intelligent terminal at present. So use terminal control lock open and close will make up for the above shortcomings. Based on this, the design to achieve three times handshake, in order to ensure the safety of the whole.

\subsection{Situation Calculus}

Situation calculus is a formal method for describing state change and action reasoning. It is assumed that all changes are produced by action, in the context of the implementation of the action s will reach a new scenario s'[7]. Different actions will produce different scenarios, so the final scene is achieved by a series of actions[8].

\section{The Construction of SILM-SC}

\subsection{Behavior Set of Safety Intelligent Lock for Safe}

The main action of safety intelligent lock for safe is unlocking and locking. Of course, it need perform other actions also. For example, in order to get the user's identity information, need to get some data about the identity. At the same time there are some abnormal behavior, including the password error 5 times into sleep.

According to the theory of the basic action of the situation calculus, we can use the following three elements to represent the action:

- $\quad \mathrm{A}=(\mathrm{ID}$, Prec, Succ)

- ID_-Name of action 
- Prec_-Precondition for action

- Succ_Effect of action execution

Table 1 Several Typical Actions of Safety Intelligent Lock for Safe

\begin{tabular}{lll}
\hline ID & Prec & Succ \\
\hline ConnectBluetooth & Bluetooth not connected & $\begin{array}{l}\text { Bluetooth connection password edit } \\
\text { box has appear }\end{array}$ \\
\hline $\begin{array}{l}\text { Send Bluetooth } \\
\text { Connection Password }\end{array}$ & $\begin{array}{l}\text { Bluetooth connection password edit } \\
\text { box has appear }\end{array}$ & $\begin{array}{l}\text { Bluetooth connection success } \\
\text { Send a Mobile }\end{array}$ \\
$\begin{array}{lll}\text { Phone Code } \\
\text { and Password }\end{array}$ & Bluetooth connection success & $\begin{array}{l}\text { Account password edit box has } \\
\text { appear }\end{array}$ \\
\hline Unlock & $\begin{array}{l}\text { Confirm open button has appear and } \\
\text { all the locks are closed }\end{array}$ & $\begin{array}{l}\text { The external door and the small } \\
\text { door of Corresponding are opened }\end{array}$ \\
\hline $\begin{array}{l}\text { Lock } \\
\text { The external door and the small door } \\
\text { of Corresponding are opened }\end{array}$ & $\begin{array}{l}\text { The external door and the small } \\
\text { door of Corresponding are closed }\end{array}$ \\
\hline Sleep & Password input error 5 times & $\begin{array}{l}\text { All modules except the processor } \\
\text { power off }\end{array}$ \\
\hline
\end{tabular}

\subsection{The Formal Description of SILM-SC}

The action of safe and intelligent lock for safe is the response action, because of the occurrence of action has the characteristics of triggering. The action will happen when the safe lock is satisfied with the condition of the action. The formal description of SILM-SC is given by situation calculus as follow based on the above action.

\subsubsection{Some Basic Actions of SILM-SC and Their Semantic Meaning}

Connect Bluetooth(b):Connect Bluetooth

Send Bluetooth Password(p):Send Bluetooth connection password

Send Phone Code(c):Send a mobile phone code

Send ID Password(d,p):Send account and password

Open $\operatorname{Lock}(\mathrm{n}):$ Unlock

Close Lock(n):Lock

\subsubsection{Some Basic Fluent of SILM-SC and Their Semantic Meaning}

Connected Bluetooth(s):In situation s connect Bluetooth success

Bluetooth Password Editor(s):Bluetooth connection password edit box appears under the scenario $\mathrm{S}$

ID Password Editor(s):Account password edit box appears under the scenario $\mathrm{s}$ 
Confirm Open Button(s):Confirm open button appears under the scenario s Lock Closed (s,n):In scenario s, the lock of number $n$ is closed Remove(s,n):In scenario s, Users are taking out items

Door Closed (s,n):In scenario $s$, the door of number $\mathrm{n}$ is closed

\subsubsection{Some Basic of precondition for action of SILM-SC and Their Semantic Meaning}

Poss (Connect Bluetooth $(\mathrm{b}), \mathrm{s}) \equiv$ Connected Bluetooth $(\mathrm{s})=\mathrm{no}^{\wedge}$

$\operatorname{LockClosed}\left(\mathrm{S}_{0}, \mathrm{n} 0\right)=$ yes $^{\wedge} \operatorname{LockClosed}\left(\mathrm{S}_{0}, \mathrm{n} 1\right)=$ yes $^{\wedge} \operatorname{LockClosed}\left(\mathrm{S}_{0}, \mathrm{n} 2\right)=\mathrm{yes}^{\wedge}$

Lock Closed $\left(\mathrm{S}_{0}, \mathrm{n} 3\right)=$ yes

Poss (Send Bluetooth Password(p),s) $\equiv$ Bluetooth Password Editor(s)=yes

Poss (Send Phone Code (c),s) $\equiv$ Connected Bluetooth $(\mathrm{s})=$ yes

Poss ( Send ID Password (d,p),s) $\equiv$ ID Password Editor(s)=yes

$\operatorname{Poss}(\operatorname{OpenLock}(\mathrm{n}), \mathrm{s}) \equiv$ ConfirmOpenButton $(\mathrm{s})=$ yes $^{\wedge} \operatorname{LockClosed}\left(\mathrm{s}, \mathrm{n}_{0}\right)=\mathrm{yes}^{\wedge}$

$\operatorname{LockClosed}\left(\mathrm{s}, \mathrm{n}_{1}\right)=\mathrm{yes}^{\wedge} \operatorname{LockClosed}\left(\mathrm{s}, \mathrm{n}_{2}\right)=$ yes $^{\wedge} \operatorname{LockClosed}\left(\mathrm{s}, \mathrm{n}_{3}\right)=$ yes

$\operatorname{Poss}(\operatorname{CloseLock}(\mathrm{n}), \mathrm{s}) \equiv \operatorname{LockClosed}(\mathrm{s}, \mathrm{n} 0)=\mathrm{no}^{\wedge} \operatorname{LockClosed}(\mathrm{s}, \mathrm{n})=\mathrm{no}^{\wedge}$ DoorClo $\operatorname{sed}(\mathrm{s}, \mathrm{n})=\operatorname{yes}^{\wedge} \operatorname{Remove}(\mathrm{s}, \mathrm{n})=$ no

\subsubsection{Some Subsequent state axiom of SILM-SC and Their Semantic Meaning}

Cause (Connect Bluetooth(b),s) $\equiv$ Bluetooth Password Editor(s)=yes

Cause(Send Bluetooth Password(p),s) $\equiv$ Connected Bluetooth $(\mathrm{s})=$ yes

Cause(Send Phone Code(c),s) $\equiv$ ID Password Editor(s)=yes

Cause(Send ID Password(d,p),s) $\equiv$ Confirm Open Button(s)=yes

Cause $($ OpenLock $(\mathrm{n}), \mathrm{s}) \equiv \operatorname{LockClosed}\left(\mathrm{s}, \mathrm{n}_{0}\right)=\mathrm{no}^{\wedge} \operatorname{LockClosed}(\mathrm{s}, \mathrm{n})=\mathrm{no}^{\wedge} \operatorname{DoorCl}$ $\operatorname{osed}(\mathrm{s}, \mathrm{n})=$ no^${ }^{\wedge} \operatorname{Remove}(\mathrm{s}, \mathrm{n})=$ yes

Cause $($ Close Lock $(\mathrm{n}), \mathrm{s}) \equiv$ Lock Closed $\left(\mathrm{s}, \mathrm{n}_{0}\right)=$ yes $^{\wedge}$ Lock Closed $(\mathrm{s}, \mathrm{n})=$ yes

\subsubsection{The Expression of SILM-SCModel}

The expression of SILM-SC model is given as follow formula (1) based on above description.

$$
\operatorname{SILM}-\mathrm{SC}=(\alpha, \varphi, \delta, \sigma)
$$

In formula (1), is the set of action, is the set of fluent, is the set of precondition and is the set of state axiom.

\section{Design of the Safety Intelligent Lock and Test of the SILM-SC}

Based on the above model, the safety intelligent lock for safe is designed and it realized the basic requirements. 
Assuming that the safe have an external door and opened the external door will have three small doors. each door is relatively independent and has its own lock, so each safe has four locks.

\subsection{Design of Unlocking Process of the Safety Intelligent Lock}

An Example of Unlocking Process of the Safety Intelligent Lock is given based on SILM-SC as follow.

If a user opens the small door 2 and close the safe after take out the document.

Initial situation:

ConnectedBluetooth $\left(\mathrm{S}_{0}\right)=$ no $^{\wedge} \operatorname{LockClosed}\left(\mathrm{S}_{0}, \mathrm{n} 0\right)=\mathrm{yes}^{\wedge} \operatorname{LockClosed}\left(\mathrm{S}_{0}, \mathrm{n} 1\right)=\mathrm{y}$ es $\wedge^{\wedge} \operatorname{Lock}$ Closed $\left(S_{0}, n 2\right)=$ yes $\wedge^{\wedge} \operatorname{Lock} \operatorname{Closed}\left(S_{0}, n 3\right)=$ yes

Procedure:

If Connected Bluetooth $\left(\mathrm{s}_{0}\right)=$ no

Connect Bluetooth(b)

Else

Bluetooth Password Editor $\left(\mathrm{s}_{0}\right)=$ yes

Send Bluetooth Password(p)

Send Phone Code(c)

If ID Password Editor $\left(\mathrm{s}_{0}\right)=$ no Send Phone Code(c)

Else

Send ID Password(d,p)

If Confirm Open Button $\left(\mathrm{s}_{0}\right)=$ no

Send ID Password(d,p)

Else

Open $\operatorname{Lock}\left(\mathrm{n}_{2}\right)$

If $\operatorname{Door} \operatorname{Closed}\left(\mathrm{s}_{0}, \mathrm{n}\right)=$ yes

Close $\operatorname{Lock}\left(\mathrm{n}_{2}\right)$

Else

While Remove $\left(\mathrm{s}_{0}, \mathrm{n}\right)=$ yes

Close Lock $\left(\mathrm{n}_{2}\right)$

\subsection{Test Result}

The test results are shown in the Table 2. 
Table 2. Test Result

\begin{tabular}{lcccc}
\hline Test Case & Normal Times & Abnormal Times & Total Times & Accuracy Rate \\
\hline Normal Lock & 98 & 2 & 100 & 0.98 \\
Forget the Password & 20 & 0 & 20 & 1.00 \\
Input Error 5 Times & 9 & 1 & 10 & 0.90 \\
Super User to Lock & 10 & 0 & 10 & 1.00 \\
\hline
\end{tabular}

The test result shows that the SILM-SC model can describe very well the logic verification process of security and control mechanism of intelligent lock.

\section{Summary}

Aiming at the problem that it lacks the effective logic verification model on the security and control mechanism of intelligent lock, this paper constructs a secure and intelligent lock model based on the situation calculus. Firstly, analysis of the realistic demand and logic relations of intelligent safety lock; Secondly, build a model using the above data. Finally according to the model design experiment and test results show that the model has a guiding role.

\section{References}

1. Liao Haiqiang. Design and application of digital anti-theft electronic mechanical lock [J]. Mechanical \& Electrical Engineering Technology, 2015 (1): 105-107(In Chinese).

2. Zhu Yujing, Li, Sun Wenjie, et al. Lock electronic lock technology review [J]. Guide of Sci-tech Magazine, 2014 (21): 285-286(In Chinese).

3. Han Tuanjun. Single-chip electronic code lock design [J]. Foreign Electronic Measurement Technology, 2010, 29 (7): 58-61(In Chinese).

4. Yuan Weichun. Access control system of RFID technology research and design based on [D]. Harbin Institute of Technology, 2015(In Chinese).

5. Yang Yulong. Design and implementation of access control system for face recognition [D]. Chongqing University, 2014(In Chinese).

6. Chen Lirong, Yang Suixian, Chen Qiang. Innovative design and manufacture of mechanical lock of card type mechanical lock [J]. Machinery Design \& Manufacture, 2016 (4): 73-75(In Chinese).

7. Liang Weisheng, Li Lei. Verification method of user interface model based on scenario calculus [J]. Computer Science, 2007, 34 (5): 260-262(In Chinese).

8. Liu Zhi. Research on virtual enterprise process modeling based on logic situation calculus [D]. Zhejiang University, 2001(In Chinese). 